\section{Association Tests of Striatal DAT Availability and SNPs That Impact a Novel Splice Variant in the DAT Gene}

TO THE EDITOR: The level of striatal dopamine transporter (DAT) availability in the human brain has been associated with polymorphisms in the gene encoding for DAT (SLC6A3) (1). We have shown that a specific allele combination for polymorphisms in the $5^{\prime}$ and $3^{\prime}$ ends of the gene affects DAT availability in a sample of young, healthy subjects; that is, an increased striatal DAT availability is associated with haplotype T-A-9R for the single-nucleotide polymorphisms (SNPs) rs2652511 and rs2937639 and the variable number of tandem repeat (2). Recently, a novel alternative splice variant was discovered in intron 3 of the DAT gene, designated E3b (3). It was demonstrated that alternative splicing of E3b can occur in postmortem human substantia nigra (3). It has not yet been demonstrated whether this novel splice variant is functional and is translated in vivo. We tested this hypothesis indirectly by investigating an association between 2 clusters of SNPs that flank the novel splice site in relation to striatal DAT availability in the previously described sample of young, healthy subjects (2). These SNPs delineate 2 common haplotypes that differentially affect E3b splicing (3). The alternative splicing incorporates multiple stop codons that cause early truncation of the DAT open reading frame and are expected to trigger nonsensemediated decay of the messenger RNA. Thus, protein products incorporating the alternative splice variant would not be predicted, and an increase in E3b splicing should lead to a decrease in total DAT (SLC6A3) messenger RNA and DAT protein.

Briefly, the sample consists of 74 Caucasian young, healthy adults, for whom striatal DAT availability was determined with ${ }^{123}$ I- $\beta$-CIT ( $2 \beta$-carbomethoxy-3 $\beta$-(4-iodophenyl)tropane) SPECT (2). Four SNPs that are associated with the novel splice variant (cluster 2: rs420422, rs462523, upstream of E3b; cluster 1: rs458609, rs457702, downstream of E3b) were genotyped for these subjects. The genotyping procedure was described earlier (3). Individual effects of these 4 SNPs and haplotype effects were analyzed with correction for age and sex using previously described methods (2). In addition, haplotypes including the previously genotyped SNPs rs2652511 and rs2937639 and variable number of tandem repeat were tested for associations. Finally, a 4-polymorphism haplotype (rs2937639-rs462523-rs458609variable number of tandem repeat) that helps delineate 2 common haplotypes was analyzed.

The analyses did not show any significant associations between the 4 newly genotyped SNPs and striatal DAT availability. Neither did we find a modifying effect of the 4 SNPs in the haplotype analyses (Supplemental Table 1; available online at http://jnm. snmjournals.org). Thus, our hypothesis was not supported. We cannot exclude that a subtle effect of the splice variant can occur in a larger sample or using other indices of DAT expression. However, the hypothesized rapid decay of the alternatively spliced product means that it would be difficult to test the hypothesis

COPYRIGHT @ 2012 by the Society of Nuclear Medicine, Inc. directly by assays of the hypothetical protein product. The role of the splice variant in human pathology is still unclear. There were initial associations with the SNP clusters linked to the splice variant and schizophrenia, but these were not supported by subsequent genomewide association studies (3). Further studies on the splice variant are necessary to demonstrate whether it has a functional role. In addition, other common or rare polymorphisms in the DAT gene, which are not covered by the currently genotyped markers, may still be associated with striatal DAT availability.

In conclusion, we do not find a significant association between 4 novel SNPs and in vivo striatal DAT availability. We suggest future studies to assess whether the novel splice variant in the DAT gene has a functional role.

\section{REFERENCES}

1. Willeit M, Praschak-Rieder N. Imaging the effects of genetic polymorphisms on radioligand binding in the living human brain: a review on genetic neuroreceptor imaging of monoaminergic systems in psychiatry. Neuroimage. 2010;53:878-892.

2. van de Giessen E, de Win MM, Tanck MW, van den Brink W, Baas F, Booij J. Striatal dopamine transporter availability associated with polymorphisms in the dopamine transporter gene SLC6A3. J Nucl Med. 2009;50:45-52.

3. Talkowski ME, McCann KL, Chen M, et al. Fine-mapping reveals novel alternative splicing of the dopamine transporter. Am J Med Genet B Neuropsychiatr Genet. 2010;153B:1434-1447.

Elsmarieke van de Giessen*

Vishwajit L. Nimgaonkar

Annie M. Watson

Chowdari Kodavali

Frank Baas

Michael W.T. Tanck

Maartje M.L. de Win

Wim van den Brink

Jan Booij

*Department of Nuclear Medicine (F2N)

Academic Medical Center

Meibergdreef 9

1105 AZ Amsterdam, The Netherlands

E-mail: e.m.vandegiessen@amc.uva.nl

Published online Mar. 16, 2012.

DOI: 10.2967/jnumed.111.100271

\section{Peptide Receptor Radionuclide Therapy in the United States}

TO THE EDITOR: We read with great interest the article by Drs. Graham and Menda titled "Radiopeptide Imaging and Therapy in the United States" published in the recent supplement to The Journal of Nuclear Medicine (1). We would like to take this opportunity to describe 2 ongoing Food and Drug Administrationapproved projects on peptide receptor radionuclide therapy at the Excel Diagnostics and Nuclear Oncology Center. 
In August 2010, the Food and Drug Administration approved an investigational new drug (IND) clinical trial (IND 78,256) using ${ }^{177} \mathrm{Lu}$-octreotate for patients with neuroendocrine cancers. Excel Diagnostics and Nuclear Oncology Center is the first facility in the United States to receive authorization to initiate this therapy. Dr. Ebrahim S. Delpassand is the principle investigator, and the project is in collaboration with St. Luke's Episcopal Hospital, Baylor College of Medicine, the Radio-Isotope Therapy of America Foundation, Biosynthema Inc., and Advanced Accelerator Application $(2,3)$. So far, we have enrolled and treated 34 patients with ${ }^{177} \mathrm{Lu}$-octreotate.

Our second active peptide receptor radionuclide therapy project under the Food and Drug Administration (IND 72,037) is for treatment of neuroendocrine cancer patients with high-dose ${ }^{111}$ In-octreotide (4). So far, we have treated more than 110 patients with inoperable metastatic neuroendocrine cancer under this protocol. The results of our treating the first 32 patients with at least 2 cycles of $18,500-\mathrm{MBq}(500-\mathrm{mCi}){ }^{111} \mathrm{In}$-octreotide were very promising and were published in 2008 (5). A manuscript describing our experience in a larger population is under review for publication.

Peptide receptor radionuclide therapy for metastatic neuroendocrine cancer using $\beta$-emitters (such as ${ }^{177} \mathrm{Lu}$ or ${ }^{90} \mathrm{Y}$ ) is very promising and needs to be brought to routine clinical practice in the United States, just like in Europe (6).

\section{REFERENCES}

1. Graham MM, Menda Y. Radiopeptide imaging and therapy in the United States. J Nucl Med. 2011;52(suppl):56S-63S.

2. Excel Diagnostics and Nuclear Oncology Center Web site. Available at: http:// exceldiagnostics.com/therapeutic-nuclear-medicine/. Accessed March 8, 2012.

3. Carcinoid Cancer Foundation Web site. Available at: http://carcinoid.wordpress. com/2010/08/24/. Accessed March 8, 2012.

4. RITA Foundation Web site. Available at: http://ritafoundationhouston.org/ research/. Accessed March 8, 2012.
5. Delpassand ES, Sims-Mourtada J, Saso H, et al. Safety and efficacy of radionuclide therapy with high-activity In-111 pentetreotide in patients with progressive neuroendocrine tumors. Cancer Biother Radiopharm. 2008;23:292-300.

6. Ambrosini V, Fani M, Fanti S, Forrer F, Maecke HR. Radiopeptide imaging and therapy in Europe. J Nucl Med. 2011;52(suppl):42S-55S.

\section{Peeyush Bhargava*}

Ebrahim S Delpassand

*Excel Diagnostics and Nuclear Oncology Center

9701 Richmond Ave

Houston, TX, 77042

E-mail: pbhargava@exceldiagnostics.com

Published online Mar. 15, 2012.

DOI: 10.2967/jnumed.112.104257

REPLY: We thank Drs. Bhargava and Delpassand for bringing our attention to their recent work in radiopeptide therapy of neuroendocrine tumors with ${ }^{177} \mathrm{Lu}$ and ${ }^{111} \mathrm{In}$. We agree that the approach is very promising and needs to be brought into clinical practice in the United States, as it is now being widely used in Europe.

\author{
Michael M. Graham* \\ Yusuf Menda \\ *University of Iowa \\ 3863 JPP Department of Radiology \\ 200 Hawkins Dr. \\ Iowa City, IA 52242-1077 \\ E-mail: michael-graham@uiowa.edu
}

Published online Mar. 19, 2012.

DOI: 10.2967/jnumed.112.104323 